\title{
Arquitetura inclusiva: experiência de projeto colaborativo
}

Inclusive architecture: a co-design experience

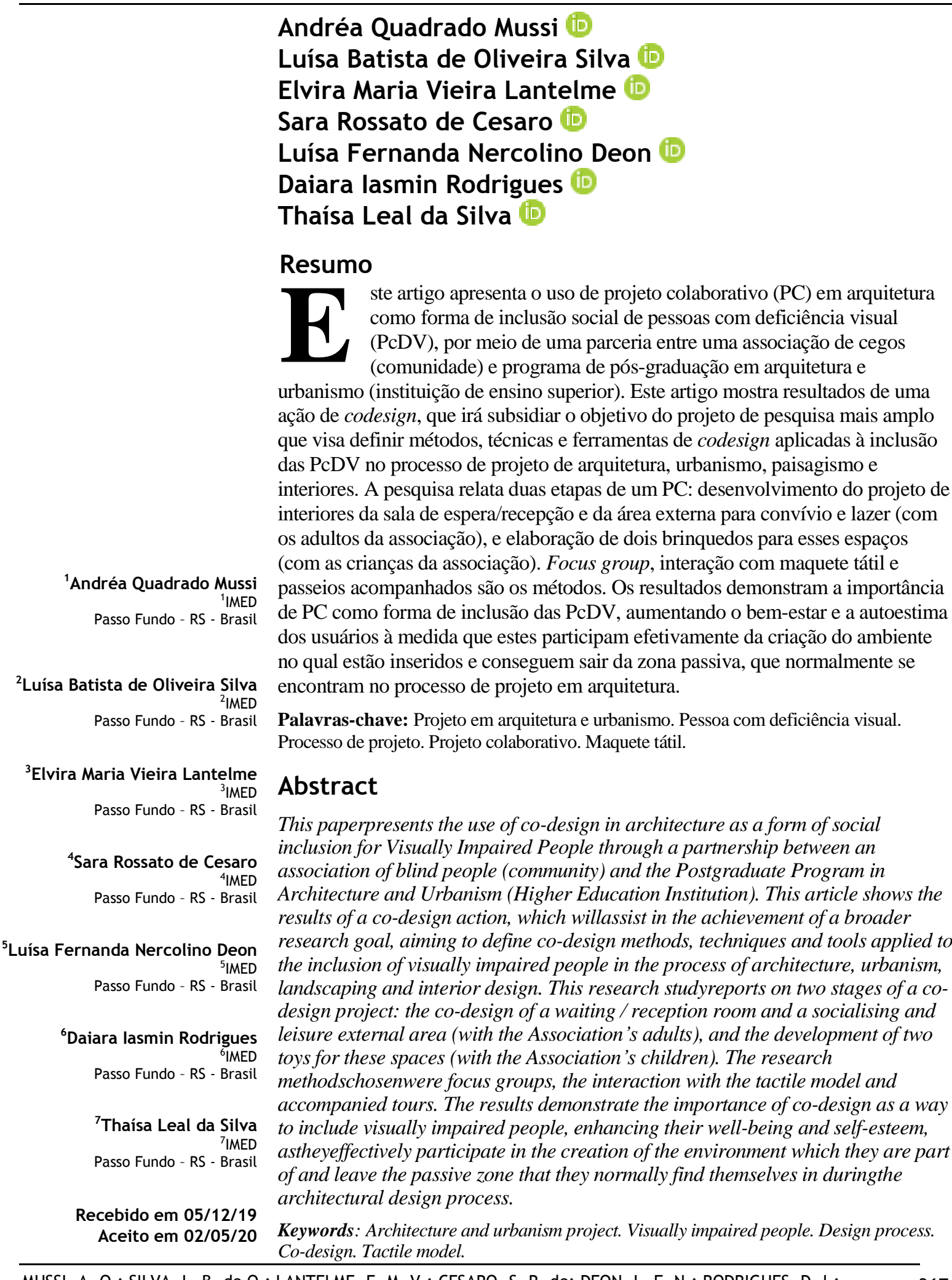

MUSSI, A. Q.; SILVA, L. B. de O.; LANTELME, E. M. V.; CESARO, S. R. de; DEON, L. F. N.; RODRIGUES, D. I.;

SILVA, T. L. da.Arquitetura inclusiva: experiência de projeto colaborativo. Ambiente Construído, Porto Alegre,

v. 20, n. 4, p. 367-386, out./dez. 2020.

ISSN 1678-8621 Associação Nacional de Tecnologia do Ambiente Construído.

http://dx.doi.org/10.1590/s1678-86212020000400478 


\section{Introdução}

Segundo Huang e Yu (2012) pessoas cegas ou com algum tipo de comprometimento visual utilizam outros órgãos sensoriais além da visão, como audição, tato e olfato, para receberem os sinais do ambiente circundante e gerarem memórias para adequada orientação espacial. Dessa forma, elas utilizam as informações que percebem no espaço para resolver seus problemas de localização.

No que diz respeito à participação das pessoas com deficiência visual (PcDV) na arquitetura, Bianchin e Heylighen (2018) afirmam que a deficiência decorre de interações das pessoas com o ambiente circundante e não dos níveis de capacidade, estado de saúde ou graus de deficiência associados a essas pessoas. Uma vez que os ambientes são passíveis de intervenções estruturais e de projeto é possível projetar e adequar os espaços de forma a torná-los acessíveis a PcDV. Entretanto, essas pessoas e suas necessidades são pouco incluídas no projeto de arquitetura, já que frequentemente somente é considerado acessível aquele espaço que apresenta soluções para pessoas com dificuldade de mobilidade.

Projetos colaborativos, no entanto, podem se tornar grandes aliados para diminuir a distância das PcDV do processo de projeto. Segundo Carneiro, Barros e Zibel (2011) a participação de usuários na concepção de um projeto possibilita discussões aprofundadas sobre as diferentes necessidades para o ambiente. Dessa forma, considerando as atividades cotidianas dessas pessoas, ampliam-se as possibilidades de projeto e podem ser realizadas trocas constantes entre os projetistas e usuários durante todo o processo de projeto.

Cavalvanti, Andrade e Silva (2011) defendem o processo de criação compartilhada, construindo projetos coletivamente, como uma maneira de identificar preferências e fortalecer o coletivo. Os projetos colaborativos arquitetônicos, portanto, aplicam-se para a identificação das preferências dos usuários e para o fortalecimento do coletivo no ambiente projetado.

Este artigo retrata uma ação de codesign ou projeto colaborativo desenvolvido com uma associação de cegos e a inclusão das PcDV no processo de projeto de paisagismo e interiores, do espaço externo e da recepção da sede atual da associação. As atividades desenvolvidas estão inseridas em um projeto de pesquisa e extensão denominado "Codesign entre projetistas do século XXI e pessoas com deficiência visual: processos e produtos". Esse projeto visa dar continuidade e maturidade aos produtos, processos de projeto e ações de codesign que vêm sendo desenvolvidos, desde 2013, em parceria com a Associação Passofundense de Cegos (APACE). As atividades desenvolvidas desde então focam a inclusão das PcDV no processo de projeto de arquitetura, urbanismo, paisagismo e interiores, na formatação de uma metodologia de codesign e de ferramentas de representação e antecipação do ambiente construído, por meio do uso de fabricação digital, prototipagem rápida e automação.

Uma das primeiras ações dentro do projeto teve o objetivo de experimentar as representações do ambiente construído com o uso de tecnologias digitais, que apoiassem a colaboração ativa dos associados no processo de projeto da nova sede da associação, incorporando a expertise das PcDV no processo (MUSSI et al., 2019, 2016).

O histórico de ações de codesign realizadas e em andamento ao longo da pesquisa pode ser classificado em: codesign na arquitetura; codesign no urbanismo; codesign em interiores; codesign no paisagismo; instrumentos, produtos e/ou programas computacionais para codesign confeccionados com tecnologias de fabricação digital, prototipagem rápida, automação e visual programming language (VPL). A Figura 1 apresenta as ações desenvolvidas durante a pesquisa desde o ano de 2013.

Este artigo descreve o estudo iniciado em 2018, que teve como resultado os projetos de interiores da recepção, da área externa de convívio e lazer da associação e dos brinquedos para esses espaços. Os resultados servem de subsídios para se alcançar o objetivo mais amplo do projeto que consiste em definir métodos, técnicas e ferramentas de codesign aplicados à inclusão das PcDV no processo de projeto de arquitetura, urbanismo, paisagismo e interiores, gerando, dessa forma, processos e produtos, com características de inovação incremental ou disruptiva.

\section{Projeto colaborativo/codesign aplicado a pessoas com deficiência visual}

Para Magnusson, Hedvall e Caltenco (2018), o projeto colaborativo (PC), também denominado codesing, induz a um maior índice de assertividade em leiautes, equipamentos e estratégias espaciais no projeto de ambientes internos e externos. Parte-se do princípio que se deve lançar um primeiro estudo de projeto a ser validado pelo usuário, dando início a um processo cíclico de reflexões sobre o que está sendo proposto até 
que se chegue a um resultado final, próximo ao ideal. O codesign possibilita ao projetista transmitir para as representações técnicas do projeto o conhecimento adquirido por meio da vivência e expertise do usuário. Heylighen e Herssens (2014) afirmam que esse processo modifica também a percepção do usuário quanto aos espaços.

Dessa forma, as ações realizadas durante o codesign seguem o intuito do design universal de atender as necessidades de toda a demanda populacional que usará um espaço, sem exclusões (FUGLERUD, 2014). Magnusson, Hedvall e Caltenco (2018) afirmam que essas ações substituem as técnicas tradicionais, denominadas como "cascata", como a entrevista que busca descobrir as carências do meio ou ambiente a ser projetado e as avaliações pós-ocupação (APO), que não são suficientes para a real inclusão das pessoas com deficiência $(\mathrm{PcD})$. Essas medidas caracterizam-se como antecipadas e não vivenciadas, como as entrevistas, ou analisadas após a construção, como a APO.

Segundo Heylighen e Herssens (2014), a supremacia da visão nos ambientes de ensino de projeto faz com que outras percepções sensoriais do corpo humano sejam desconsideradas, ao passo que a representação dos projetos se dá por meio de desenhos que, no máximo, apresentam qualidades de conforto ambiental, térmico e acústico. Dessa forma, faz-se necessário que quando trabalhado um projeto arquitetônico com usuários que não possuam a visão como forma de compreensão de espaços, sejam usados métodos que consigam transcrever técnicas visuais para sensitivas, como, por exemplo, as imagens de maquetes computadorizadas de um ambiente transcritas na forma de maquetes táteis (FUGLERUD, 2014). Segundo Heylighen e Herssens (2014), a arquitetura deve rever tais princípios e os projetistas devem propor alternativas que tornem as edificações mais atrativas em quesitos não visuais. Por exemplo, pode-se utilizar na concepção espacial pisos diferenciados que direcionem o sentido dos fluxos ou jogos de volumes na edificação para proporcionar emissões de sons que influenciem em rotas direcionais.

Exemplos exitosos de uso da composição formal dos espaços, objetos e mobiliários para a inclusão social, fomentando o diálogo e a compreensão do usuário com deficiência visual, podem ser observados no projeto da primeira escola para PcDV nos Estados Unidos da América, a Perkins School for the Blind. Podem ser observados volumes internos com pés-direitos diferentes que buscam criar distintos efeitos sonoros e sensações cinestésicas ao permanecer ou transitar nesses locais (Figura 2) (informação verbal ${ }^{1}$ ).

Figura 1 - Histórico do projeto de pesquisa

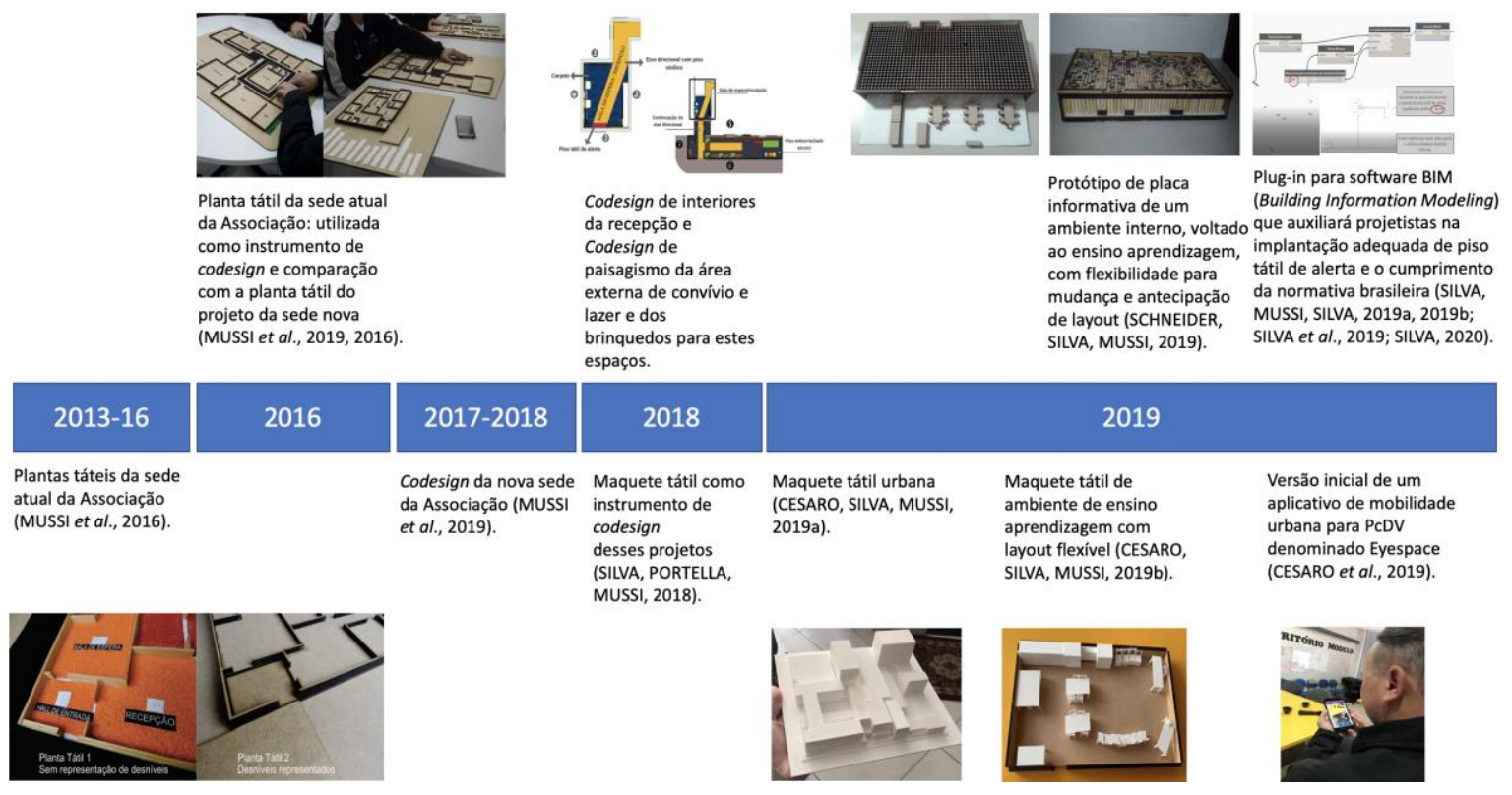

1Entrevista concedida por Kevin Hartigan. Entrevista Kevin Hartigan sobre Perkins School for the Blind. [Apr. 2018]. Entrevistadora: Andréa Quadrado Mussi. Watertown, 2018. 1 arquivo .mp3 (60 min.). 
Figura 2 - Volumes internos com diferentes pés-direitos, texturas e disposição de janelas

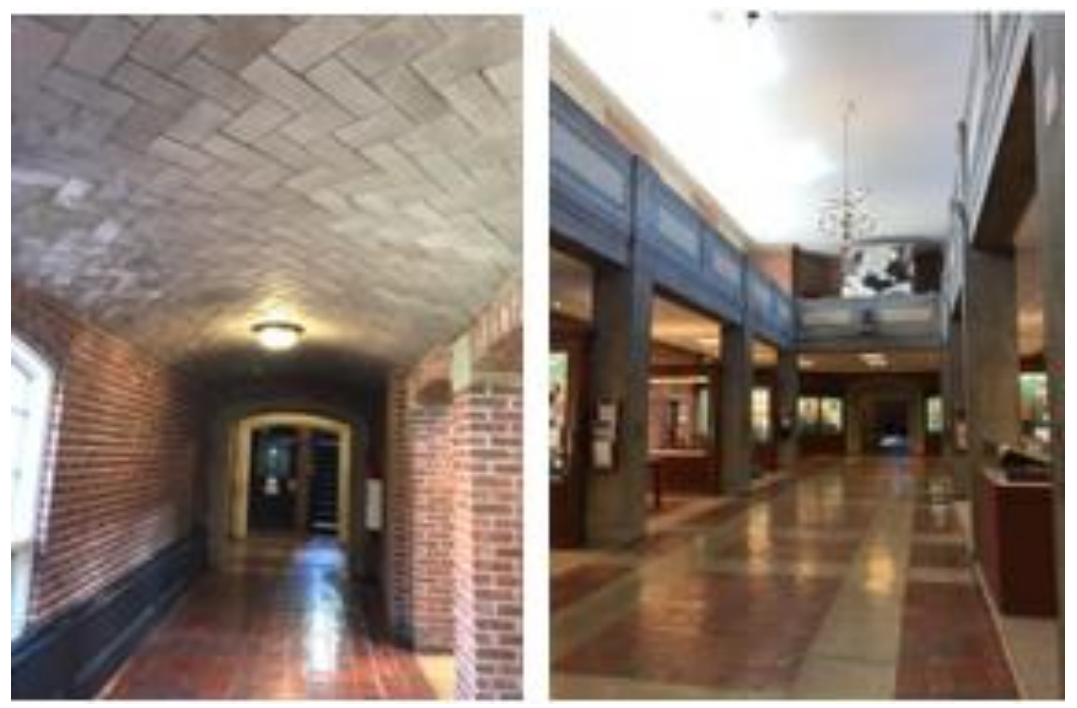

Os espaços construídos mais recentemente na PerkinsSchool for theBlind, apesar de não utilizarem integralmente a mesma diferenciação, mantêm o uso de diferentes texturas de pisos (marcação de acesso) e empregam marcadores discretos (Figuras 3a e 3b), iluminação difusa e sinalética inclusiva com cinco modos de comunicação (Figura 3c). A comunicação e interação são incentivadas e potencializadas pelo projeto dos mobiliários executados para a escola. Exemplo disso é uma mesa com cadeira na cor rosa e com adesivos de princesa executada para uma criança cega. A cor e os adesivos são uma forma de comunicação com terceiros, que é incentivada no momento que as pessoas com visão indagam à criança sobre a temática "princesas" (Figura 4), iniciando assim o diálogo e a interação (informação verbal ${ }^{2}$ ).

O codesign é uma aproximação do projetista com a expertise que o usuário com deficiência visual possui sobre os espaços que usa ou deixa de usar. A metodologia possibilita a interação durante a construção de um projeto, antecipando a memória espacial e oportunizando a vivência do ato de concepção pelo diálogo e pela manipulação de recursos de representação, tais como plantas e maquetes táteis.

As estratégias usadas nas metodologias de codesign aplicadas com PcDV fazem uso da própria bengala para interpretar os ambientes físicos e de canetas de leitura e adesivos RFID, além do uso do zoom para PcDV com baixa visão, aplicados em jogos, textos ou qualquer interação virtual necessária durante a aplicação da metodologia (HOURCADE, 2008). Destaca-se que essas atividades de codesign realizadas in loco e não virtuais são mais efetivas por conseguirem capturar a realidade dos usuários no espaço e transmiti-las diretamente aos projetistas (HEYLIGHEN; HERSSENS, 2014).

No trabalho com crianças, Hourcade (2008) destaca os métodos e pormenores que devem ser avaliados para que as ações resultem em um codesign produtivo tanto para projetistas como para usuários. Naturalmente, crianças possuem variações de humor mais repentinas e são mais impacientes durante as atividades propostas do que os adultos, o que torna o processo mais complexo. Outro ponto a considerar é que, dependendo da idade, o grupo todo ou parcela dele podem não ser alfabetizados, gerando a necessidade de se usar recursos mais dinâmicos e de fácil entendimento, pelo menos para a primeira impressão. Com o passar do tempo, conforme as pessoas se familiarizam com os métodos, pode-se utilizar recursos mais atrativos e, consequentemente, mais complexos. Para realizar essas atividades com crianças que apresentam comprometimento e dificuldades visuais, as estratégias devem ser ainda mais elaboradas, pois muitas crianças, se não tiverem recebido os incentivos certos durante seu desenvolvimento, podem apresentar características de introspecção e menor envolvimento.

${ }^{2}$ Entrevista concedida por Kevin Hartigan. Entrevista Kevin Hartigan sobre Perkins School for the Blind. [Apr. 2018]. Entrevistadora: Andréa Quadrado Mussi. Watertown, 2018. 1 arquivo .mp3 (60 min.). 
Figura 3 - (a) Marcador localizado no corredor para indicar à pessoa com deficiência visual que existe uma porta em frente a esse marcador; (b) detalhe do marcador que dialoga também com quem enxerga; e (c) cinco tipos de sinalética (em relevo, dois tamanhos de desenho/função, em 3D, em braile ao lado do número)

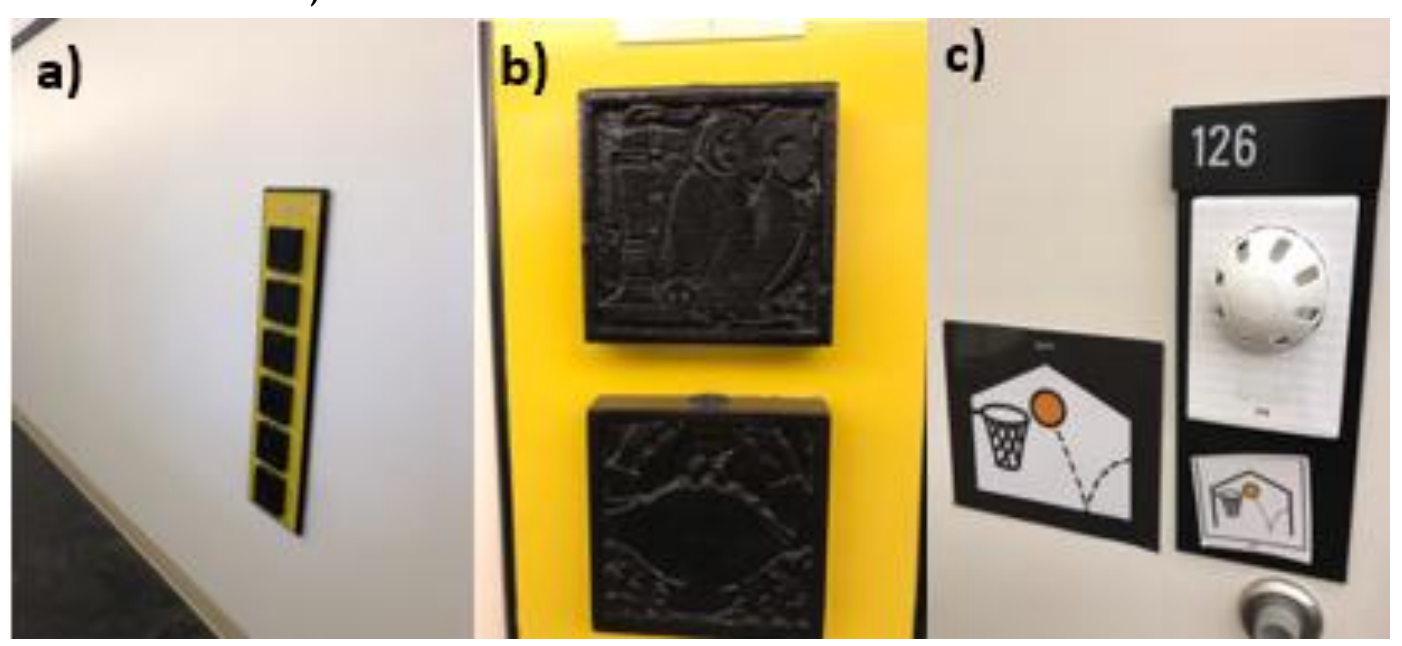

Figura 4 - Mobiliário de papelão pintado e com adesivos executado na Perkins School for Blind - à esquerda com tampo preto para criança com baixa visão e à direita mesa e cadeira rosa com adesivos de princesa para criança cega

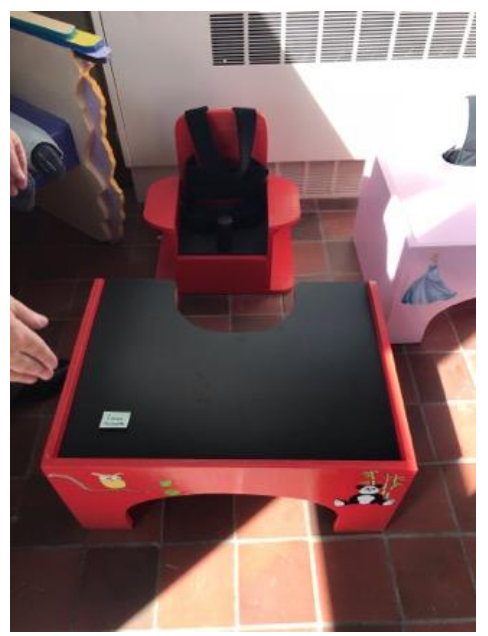

Entretanto, os projetos colaborativos podem e devem ser aplicados a qualquer grupo humano para serem realmente inclusivos. Fuglerud (2014) intitula isso como "usabilidade universal", que tem como conceito principal o uso dos ambientes e produtos por diferentes pessoas, adaptando-os a todos os grupos. A usabilidade se difere da acessibilidade por ser um conceito que busca, além da aplicação de diretrizes de acessibilidade universal, o uso real e a interação autônoma dessas pessoas com os ambientes, sem que elas precisem de adaptações ou auxílio para utilizá-los.

Deve-se salientar, contudo, que os resultados obtidos pelo uso do codesign não são e não devem se tornar uma verdade absoluta, visto que o perfil dos usuários, os conhecimentos técnicos dos arquitetos, além do espaço físico construído, estão suscetíveis a mudanças (MAGNUSSON; HEDVALL; CALTENCO, 2018). Por isso, o codesign deve ser considerado como um longo e ininterrupto processo de atualização das necessidades dos usuários que só é possível, segundo Caixeta e Fabrício (2018), por meio de um processo participativo que utiliza várias técnicas que permitam resultados mais assertivos ao longo de seu desenvolvimento.

Além das dificuldades e condicionantes específicas encontradas durante a realização de projetos colaborativos com PcDV, também existem outros pontos importantes inerentes a todo e qualquer processo de colaboração entre os profissionais que detêm o conhecimento técnico e os leigos, como as representações 
gráficas técnicas dos arquitetos (profissionais) que não são facilmente passíveis de entendimento pelos usuários (leigos). Como forma de mitigar essas condicionantes limitadoras em um projeto participativo, os métodos e técnicas utilizados devem ser adaptados conforme a necessidade da realidade local (CAIXETA; FABRÍCIO, 2018). Na metodologia desenvolvida durante a pesquisa apresentada neste artigo foram usadas a prototipagem e a maquete tátil como métodos principais, adaptados à realidade dos usuários e capacidades dos projetistas.

\section{Método}

O artigo apresentado é de natureza qualitativa, do tipo pesquisa em campo, pois é capaz de extrair dados e informações diretamente da realidade do objeto de estudo. A pesquisa faz uso do PC, que Caixeta e Fabrício (2018) apontam ser uma metodologia eficaz para envolver usuários em um processo de projeto que busca compreender e aprender com o usuário a sua expertise.

O processo de concepção do PC da sala de espera/recepção e do espaço externo ocorreu em três momentos: no focus group (FG), associado a entrevista semiestruturada, na interação com a maquete tátil e nos passeios acompanhados. Esse processo se somou a outras interações, ações de codesign, workshops e desenvolvimento de aplicativo realizados entre os projetistas e as PcDV (MUSSI et al., 2019, 2016; CESARO; SILVA; MUSSI, 2019a, 2019b; CESARO et al., 2019; SILVA; PORTELLA; MUSSI, 2018).

As participações que nortearam inserções no projeto ou modificações vieram tanto das diversas interações que o grupo de pesquisa mantém com a associação há mais de seis anos ${ }^{3}$, doFG e entrevistas semiestruturadas, dos três passeios acompanhados (no reconhecimento dos espaços a requalificar, quando do tateamento da maquete tátil o relacionando com o espaço e na validação final do projeto) e no tateamento da maquete tátil da proposta (com debate simultâneo).

Para a realização das discussões foi escolhido o método de FG, o qual busca, por meio da definição de tópicos norteadores, encaminhar as discussões sobre determinado tema.

A pesquisa foi realizada por meio de um projeto colaborativo (PC), envolvendo adultos e crianças. Com os adultos foi desenvolvida uma proposta de projeto para melhoria da sala de espera/recepção e de uma área externa para convívio e lazer. Com as crianças, elaborou-se dois brinquedos, um a ser colocado na sala de espera/recepção e outro na área externa de convívio. Importante ressaltar que o brinquedo da área externa foi elaborado como pré-teste por alunos de graduação em arquitetura e possui possibilidade de alterações que dependerão dos resultados encontrados. Em ambos os projetos colaborativos ocorreram a realização de FG concomitante à entrevista semiestruturada para a obtenção de informações.

Contudo, como se trata de atividades com peculiaridades distintas, o projeto colaborativo foi separado nas etapas com adultos e com crianças, conforme demonstrado nas Figuras 5 e 6.

A primeira fase consistiu em visita ao local, medições dos espaços e inventário do mobiliário existente e análise do espaço pelos pesquisadores (que também atuaram como projetistas durante a pesquisa), além de elaboração do briefing utilizando o método FG, escolhido por permitir encaminhar a discussão com os usuários, por meio da definição de tópicos norteadores. Os tópicos norteadores para o FG foram referentes a função, piso, móveis e satisfação, aliados a entrevistas semiestruturadas. As perguntas utilizadas para direcionar o FC para a área interna foram: "Como o espaço é utilizado? Quantas pessoas o utilizam? O que é necessário para uso deste espaço? Quais aspectos precisam melhorar no espaço? Percepção quanto à qualidade do piso e mobiliário?". Para a área de convívio/lazer da área externa foram elencados os seguintes tópicos norteadores: "O que é necessário para que a área externa se torne convidativa para os associados? O que se planeja para ela? As crianças conseguem brincar com segurança? O que seria prazeroso para se fazer no local? Que atividades gostariam de realizar nela? Que elementos físicos necessitam ser melhorados para utilização com segurança?”.

\footnotetext{
${ }^{3} \mathrm{~A}$ instituição de ensino superior IMED possui um convênio de cooperação mútua e autorização de pesquisa com a Associação Passofundense de Cegos desde 2013, renovada em 2019. Todos os participantes da pesquisa nos workshops, focus group e passeios acompanhados assinaram termo de consentimento livre e esclarecido lido em voz alta com a presença de testemunhas. Toda a documentação foi apresentada na revisão do referido artigo e também está em domínio da líder do grupo de pesquisa e na secretaria da associação.
} 
Figura 5 - Infográfico do projeto colaborativo

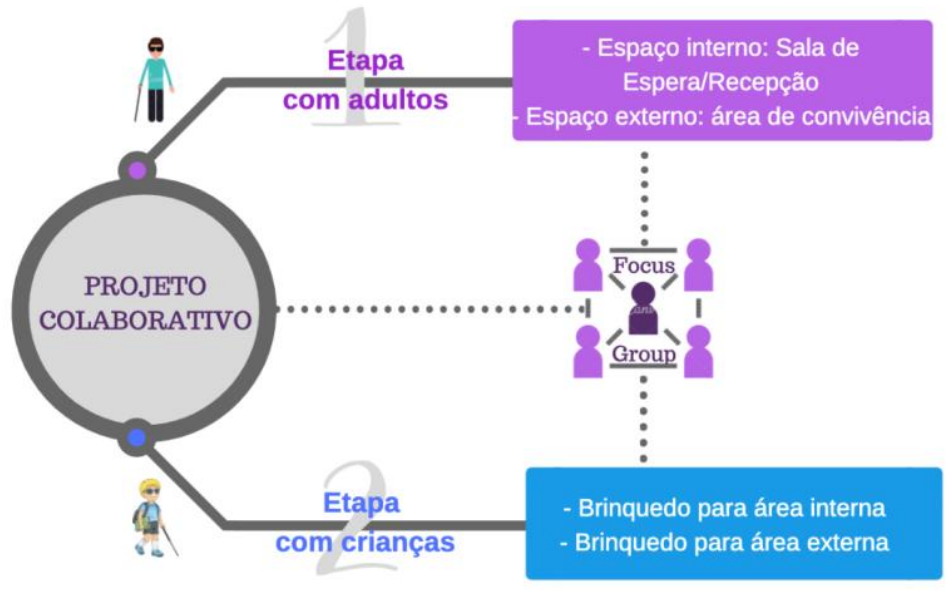

Figura 6 - Infográfico das fases do projeto colaborativo com os adultos Fases do Projeto colaborativo - adultos

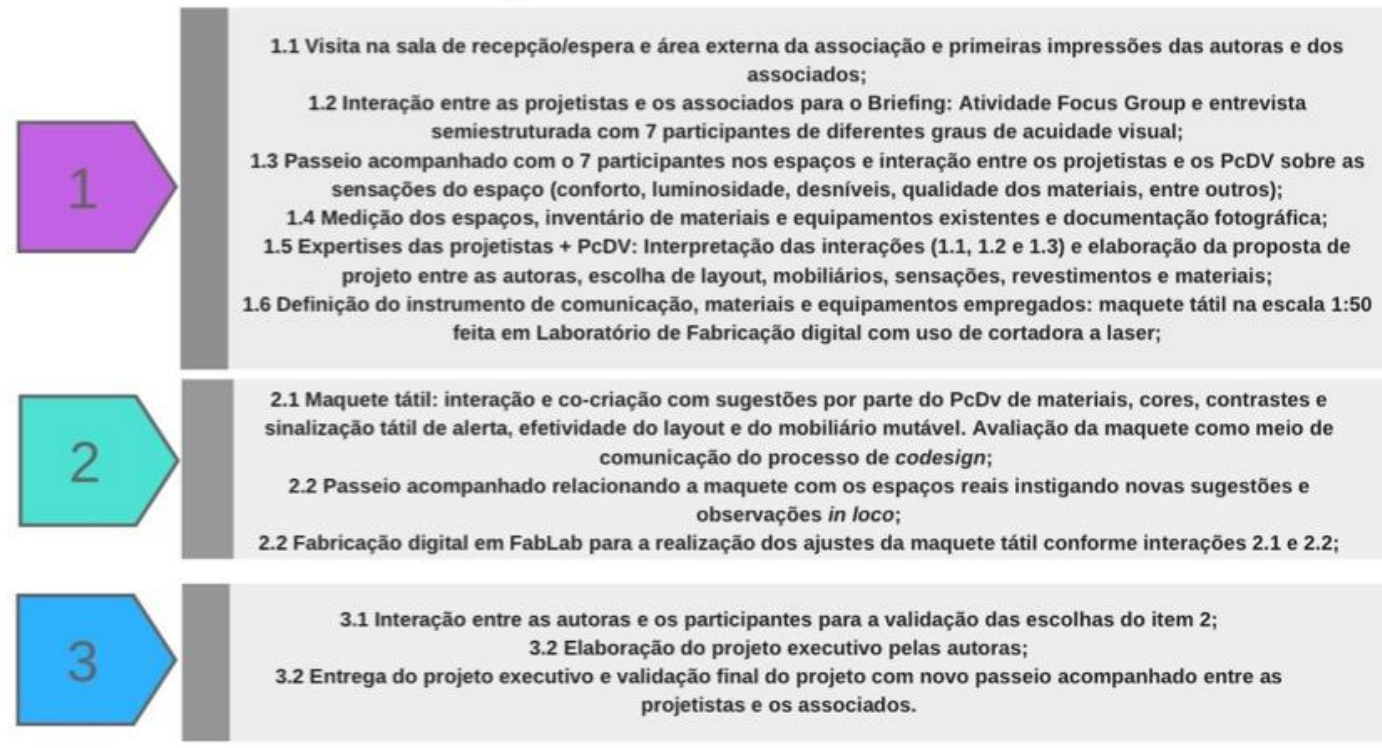

Participaram do FG e das entrevistas semiestruturadas 7 (sete) membros da associação, no grupo etário de 25 a 50 anos, divididos da seguinte maneira: dois participantes cegos, sendo um deles homem e um deles mulher, quatro participantes com baixa visão, com diferentes graus de acuidade visual, sendo um homem e 3 (três) mulheres e uma colaboradora voluntária da associação. A dinâmica aconteceu na sala de leituras da associação, avançando dos tópicos mais gerais até os tópicos mais específicos, conforme relatado em Morgan (1997). A atividade teve duração de 1 hora e foi gravada com permissão dos participantes para posterior transcrição e análise.

$\mathrm{Na}$ fase 1 também foram realizados passeios acompanhados no local com os participantes a fim de observar o uso e a qualidade do espaço. A fase 1 ainda compreendeu a interpretação dos dados levantados e a elaboração da proposta de projeto.

A fase 2 do estudo compreendeu a fabricação da maquete tátil, a interação dos usuários com essa representação do espaço e a avaliação da maquete como meio de comunicação no processo de codesign. A maquete tátil foi confeccionada em laboratório de fabricação digital, com materiais que representassem a textura dos elementos e objetos contidos no projeto e não oferecessem riscos para serem manuseadas pelas PcDV. A maquete foi fabricada em cortadora a laser com MDF de $6 \mathrm{~mm}$ e composta de diferentes tecidos para representar as texturas. A maquete tátil foi utilizada como meio de interação entre os projetistas e as 
PcDV e não como mera representação final do projeto, tendo sofrido modificações a partir dos feedbacks dos usuários.

A fase 3 compreendeu a interação dos projetistas e os usuários para a validação das escolhas na fase anterior, por meio da apresentação do projeto executivo dos espaços e a realização de um novo passeio acompanhado.

Por sua vez, a etapa do PC com o grupo de crianças teve como objetivo desenvolver elementos recreativos que explorassem as principais habilidades necessárias ao desenvolvimento e que, ao mesmo tempo, oferecessem oportunidades de interação entre as crianças atendidas pela associação e crianças que, eventualmente, frequentam a associação acompanhando algum familiar.

Conforme descrito na Figura 7, essa etapa foi realizada em única fase, utilizando o FG para briefing das necessidades dos usuários. Os responsáveis pelas crianças também participaram da dinâmica e puderam realizar recomendações importantes em momentos pontuais da atividade. Participaram 5 (cinco) crianças (uma de 5 anos, três de 6 anos e uma de 12 anos de idade) com seus respectivos responsáveis.

Além da atividade de FG também aconteceu a experimentação do brinquedo a ser adaptado. O brinquedo havia sido projetado e confeccionado previamente por alunos de graduação em arquitetura e urbanismo, e foi alterado nas interações durante o PC.

\section{Resultados e discussões}

\section{Projeto colaborativo: etapa com adultos}

Conforme descrito no método, a primeira atividade realizada para a apropriação das necessidades para a melhoria da sala de espera/recepção e para a área externa de convívio e lazer da associação foi a atividade do FG (Figura 8).

Figura 7 - Infográfico das fases do projeto colaborativo com as crianças

\section{Fases do Projeto colaborativo - crianças}

Figura 8 - Focus group com adultos

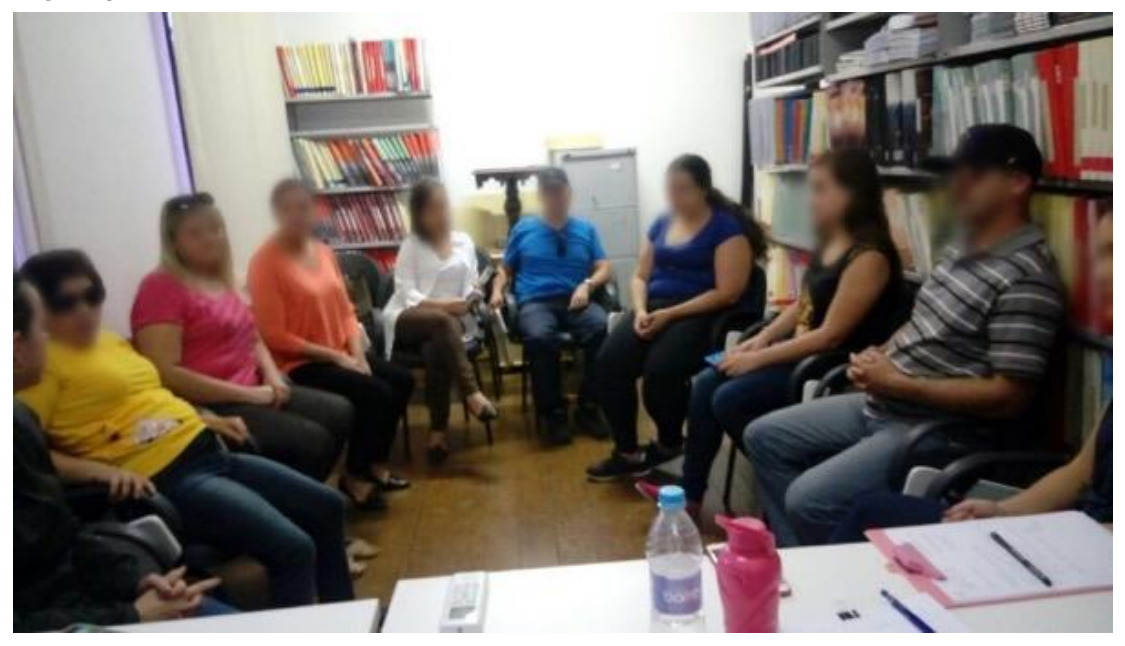


Um dos tópicos debatido pelos participantes relaciona-se às condições do piso. Os participantes apontaram não existir nenhum tipo de sinalização tátil no acesso à sala de espera/recepção, e que ainda, para maior dificuldade, possui um degrau. Também foi relatado que, devido à associação estar inserida em uma casa antiga, cedida pela prefeitura, ela possui um piso com muitas irregularidades. Esse primeiro tópico foi desafiador, visto que, embora os participantes tivessem real conhecimento do espaço, foi necessário questioná-los sobre quais as medidas seriam mais interessantes para ajudar não só as PcDV já frequentadoras da associação, mas as novas que poderiam vir a conhecer e necessitar utilizar o espaço. Esse tópico foi de extrema importância para a elaboração da proposta para o piso que teve um projeto definido com diferenciação de cores e texturas.

O segundo tópico debatido foram os móveis existentes na sala: os participantes também se demostraram insatisfeitos com a falta de aconchego da sala devido à falta de poltronas confortáveis, e também devido à falta de um local para disponibilizar água, café ou outra refeição rápida, já que muitas vezes os associados precisam fazer longas esperas entre os turnos de suas atividades.

O último tópico debatido trata do espaço disponível que, segundo os participantes, não possui nenhum tipo de conforto e que é insuficiente para as atividades ali desenvolvidas, que não são somente de espera, mas também a sala é utilizada para conversas e interação entre os associados, que a usam para tocar instrumentos musicais e cantar, bem como para a venda de produtos que ajudam na manutenção da associação.

Uma última questão levantada pelos participantes é o incômodo sentido pelo barulho vindo da rua que atrapalha as aulas de leitura.

A Figura 9 apresenta a síntese das questões levantadas na percepção dos usuários e representam parâmetros de projeto baseados na expertise das PcDV. Esses tópicos foram os mais relevantes utilizados na elaboração da proposta do projeto.

O passeio acompanhado e a interação com as PcDV para reconhecimento do espaço em seguida da realização dos $F G$ permitiram observar os trajetos usados dentro do espaço, que ocorre em diagonal pela recepção, ligando a porta de acesso à circulação adjacente, bem como detectar o desconforto percebido pelas PcDV, baixa visão em relação a uma forte luminosidade oriunda da janela. Essa condição de excessiva luminosidade era causada por uma parede cega de um edifício em altura situado em frente a essa janela da sala de recepção. Pintada na cor bege, essa parede reflete a incidência solar, gerando o desconforto mencionado. As PcDV relataram também a necessidade de uma sinalização ou marcadores na parede próxima à recepção que faz divisa com o banheiro para melhorar a demarcação do acesso a esse cômodo.

Considerando esses tópicos, partiu-se para o desenvolvimento do anteprojeto da sala de recepção. Em relação ao piso, optou-se pela demarcação de um eixo em material vinílico na cor amarela, ligando a porta de acesso da recepção aos outros ambientes adjacentes, contrastando com um piso acarpetado na cor azul, no restante da sala (Figura 10). As cores azul e amarela promovem a percepção de contraste, bastante favorável às pessoas com baixa visão, enquanto as diferentes texturas do vinil e do carpete facilitam o deslocamento e direcionamento das pessoas cegas.

O piso tátil direcional não foi utilizado, uma vez que durante o passeio acompanhado as pessoas mencionaram não ser útil naquela situação. Manteve-se, entretanto, o piso de alerta para sinalizar o degrau de acesso à recepção. Optou-se em conjunto com os associados a diferença de textura e de cor como uma pista de direcionamento.

A decisão pelo eixo em vez do piso tátil direcional, conforme prescreve a norma brasileira NBR 16537 (ABNT, 2016), foi tomada com base em estudos desenvolvidos dentro do projeto de pesquisa sobre a efetividade do piso direcional como um elemento de orientação para PcDV (SILVA; PORTELLA; MUSSI, 2018).

Pesquisas realizadas nos Estados Unidos da América (EUA), que deram origem ao termo barriersfree design $e$ ao conceito do desenho universal, demonstram a baixa eficácia do piso tátil direcional e a utilização somente do piso tátil de alerta. Os EUA são referência em pesquisas sobre elementos e ferramentas para orientação de PcDV (LAHAV; MIODUSER, 2004; LAHAV; SCHLOERB; SRINIVASAN, 2009) e possui os mais importantes programas de orientação e mobilidade para PcDV e laboratórios específicos para estudar e compreender os processos de orientação espacial das PcDV. 
Figura 9 - Tópicos principais levantados por meio do focus group

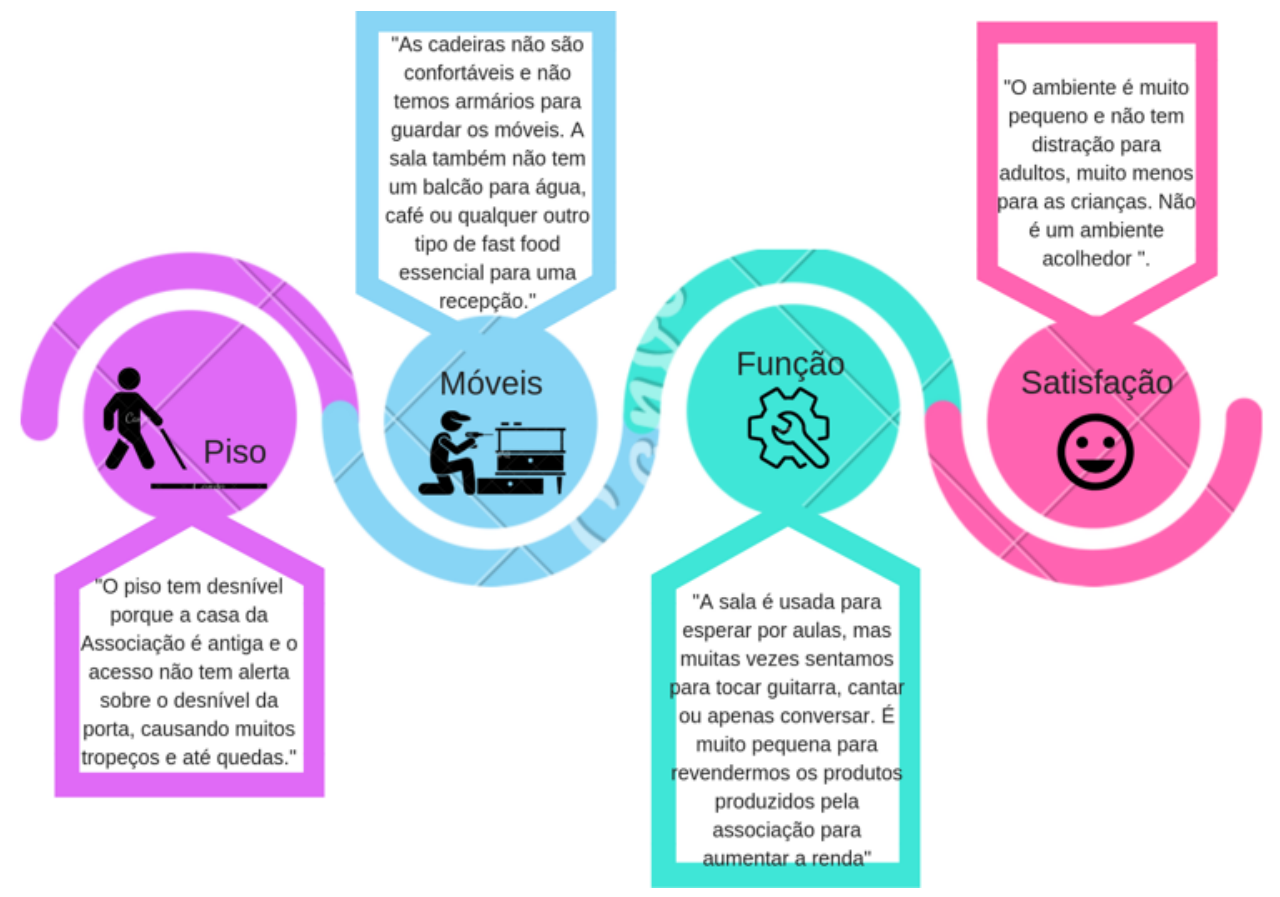

Figura 10 - Leiaute com a descrição das texturas de piso e vistas da sala de recepção/espera

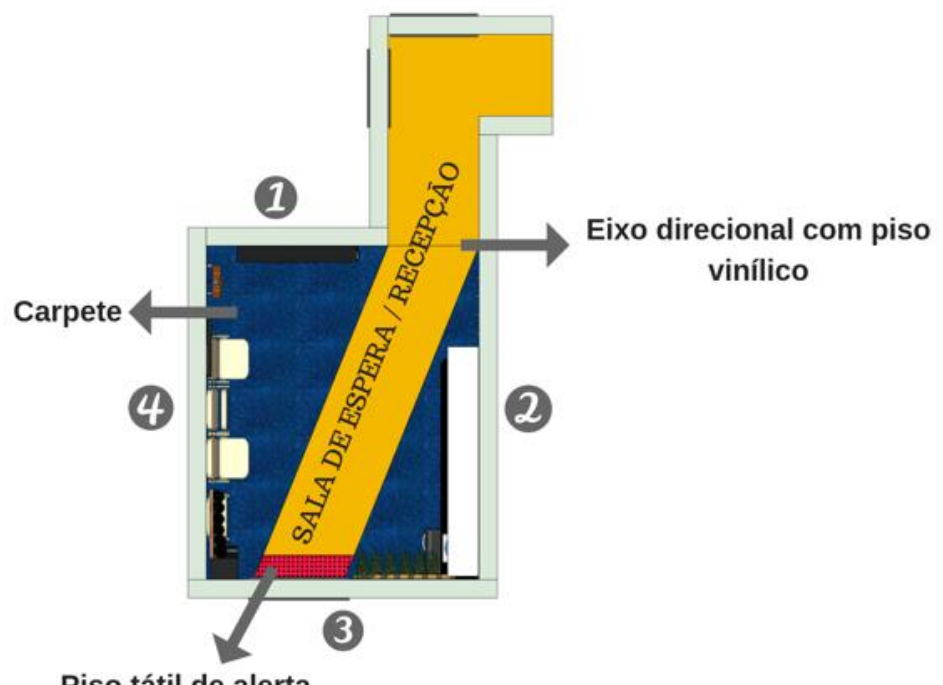

Na Perkins School for the Blind, por exemplo, há diversos exemplos de usos de diferentes texturas e contrastes nos pisos sem o uso de piso tátil direcional, como recomendado pela normativa brasileira (ABNT, 2016). Conforme se observa nas Figuras 11, 12 e 13, os ambientes dessa escola apresentam diferenciação entre o acesso principal (carpete em placa), as circulações gerais, os ambientes internos (Figuras 11b e 11c) e os ambientes amplos, utilizando direcionamento por contraste de cores e texturas (Figuras 11a e 12).

O pouco uso do piso tátil direcional e sua supressão nas normas técnicas do país, conforme explica um dos diretores da Perkins (informação verbal ${ }^{4}$ ), considera os princípios do desenho universal, pois esse tipo de piso provoca incômodos para pessoas em cadeira de rodas. Além dos pisos táteis de alerta, as normas

${ }^{4}$ Entrevista concedida por Kevin Hartigan. Entrevista Kevin Hartigan sobre Perkins School for the Blind. [Apr. 2018]. Entrevistadora: Andréa Quadrado Mussi. Watertown, 2018. 1 arquivo .mp3 (60 min.). 
técnicas do país recomendam o uso de marcadores discretos, guias de balizamento (como as fachadas internas contínuas em corredores) e maquetes táteis (Figura 13c), como parte da política do país de investimento em treinamento e promoção da autonomia das PcDV nos espaços edificados.

No Brasil, uma pesquisa iniciada em 2012 no estado de São Paulo (ABATE; KOWALTOWSKI, 2017) constatou que a implantação da sinalização tátil de piso nas áreas de circulação de escolas que incluem alunos com deficiência visual requer a familiarização com o uso; o que deve ser obtido por meio de treinamento de orientação e mobilidade, associado a outros instrumentos como o mapa tátil. Observa-se, portanto, nas pesquisas realizadas no Brasil e nos EUA, o consenso em torno da necessidade de treinamento e familiarização das PcDV com o ambiente construído onde irão se deslocar, devendo, para isso ser usados recursos como as maquetes e mapas táteis.

Da mesma forma, na pesquisa realizada neste estudo os participantes externaram sua preferência por guias de balizamento e diferenças de textura para sua melhor mobilidade nos espaços edificados. No FG e nos passeios acompanhados os participantes descreveram ser incômoda a utilização do piso tátil direcional e o citaram ainda como algo "inutilizável” por eles. Destacaram, contudo, a importância do piso tátil de alerta que identifica portas de acesso e obstáculos. Por isso, no projeto da sala de espera foi definida a colocação de piso tátil de alerta somente na porta de acesso à sala (Figura 14).

Figura 11 - Perkins School for the Blind: (a) contraste de pisos na ala de exposições, (b) diferença de cores e texturas entre hall e corredor e (c) detalhe

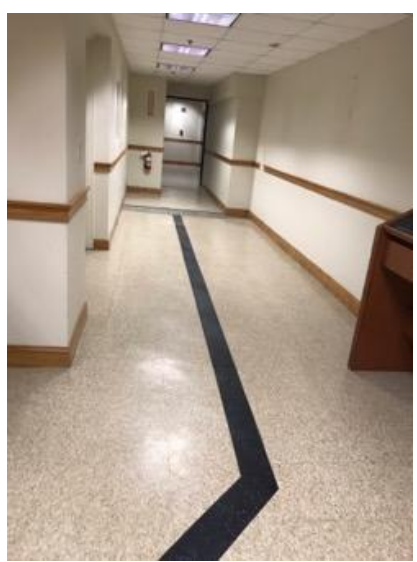

(a)

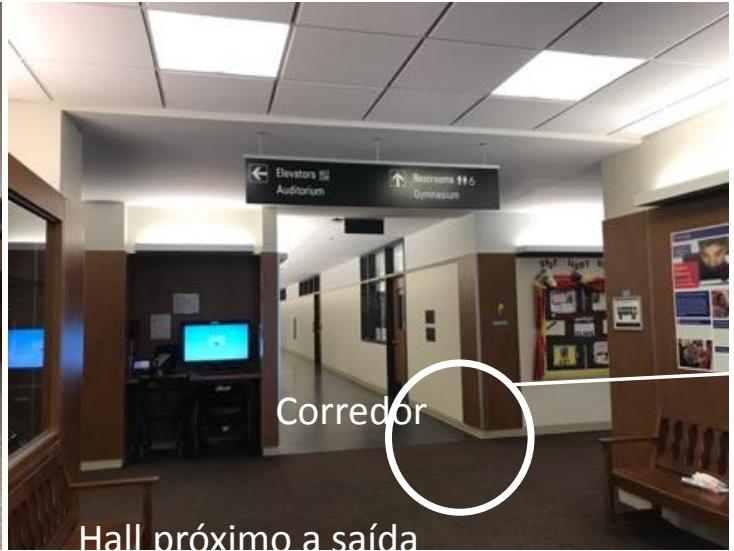

(b)

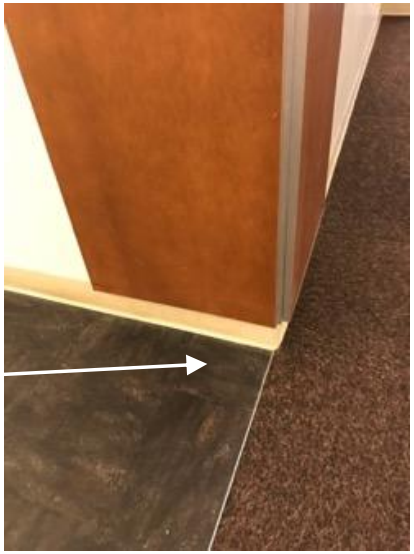

(c)
Figura 12 - Perkins School for the Blind

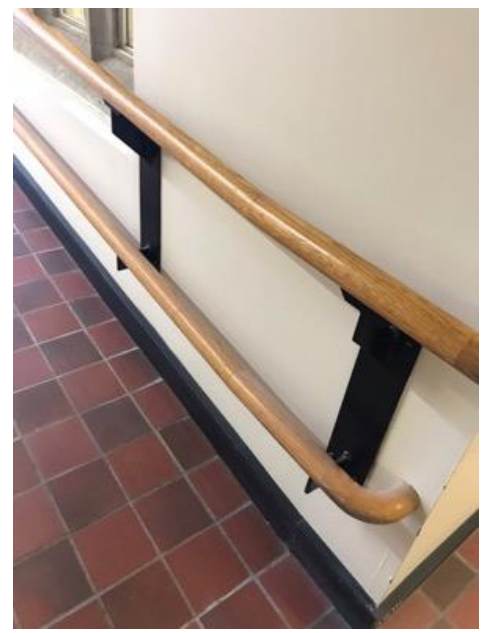

(a) Contraste em rodapé

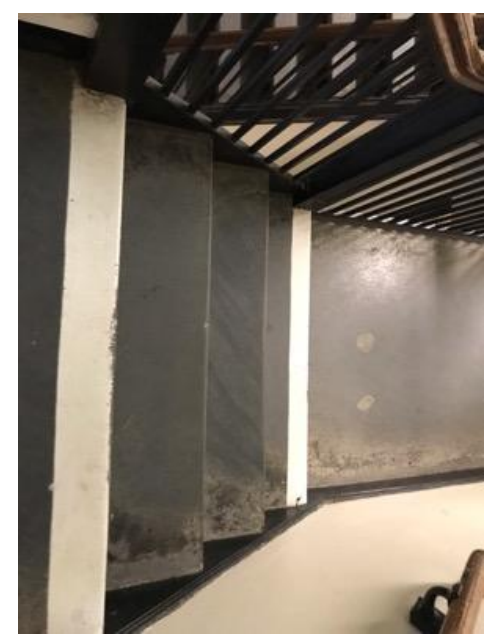

(b) Contraste nos degraus da escada e marcação dos patamares 
Figura 13 - Perkins School for the Blind

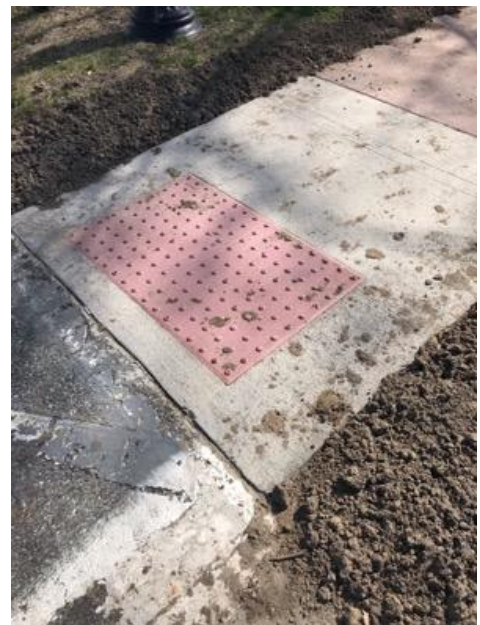

(a) Piso tátil de alerta em passeio público do entorno

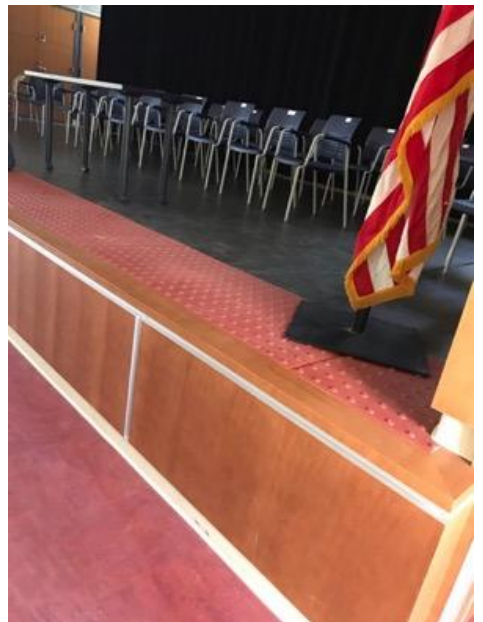

(b) Piso tátil de alerta no palco do auditório

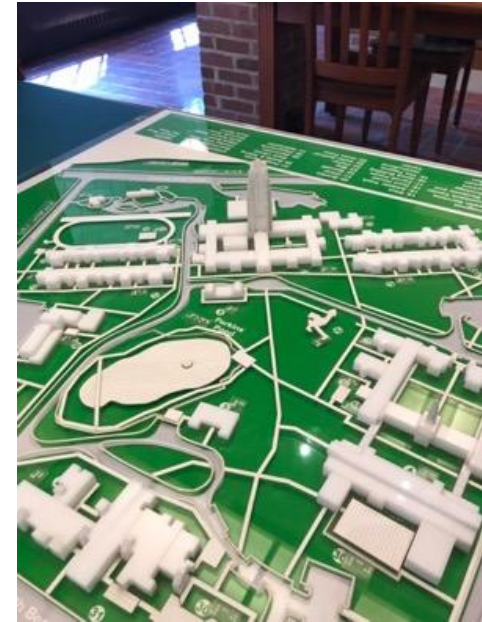

(c) Maquete tátil

Figura 14 - Detalhamento das vistas 1 e 2 da sala de recepção/espera

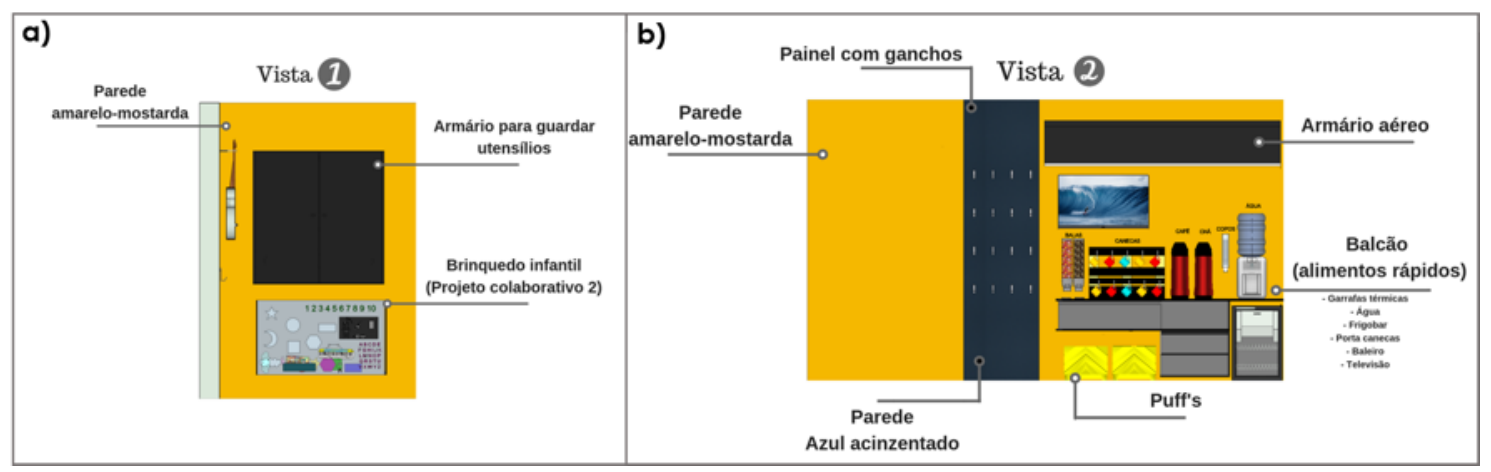

Para descrição do projeto, cada uma das vistas será apresentada e explicada individualmente. Na Figura 10, apresentada anteriormente, encontra-se o leiaute da sala de espera/recepção e o eixo direcional formado pela composição de pisos e a numeração das vistas descritas a seguir.

Na vista 1 (Figura 14a) pode-se observar a instalação de um armário para pequenos utensílios, no qual podem ser armazenados objetos necessários às atividades de venda de produtos da associação. O armário possui a mesma espessura do brinquedo localizado logo abaixo. As cores das paredes, assim como as do piso, foram decididas e testadas pelos participantes durante as atividades do PC. Essas cores foram decididas em conjunto para que não ocasionasse confusão para nenhum associado e para que se adaptasse a todas as diferenças de acuidade visual, sem ocasionar confusão de informações. O brinquedo presente nessa vista do projeto faz parte do PC número dois.

$\mathrm{Na}$ vista 2 (Figura 14b) houve composição de cores para a parede, sendo elaborado um painel na cor azulacinzentado para a colocação de ganchos, que serão utilizados para pendurar sacolas com produtos vendidos durante os finais de semana, bem como apoio para pendurar bengalas no dia a dia. Também houve a elaboração de um balcão para que possam ser oferecidos alimentos rápidos como café, água, balas, etc. A colocação desse balcão foi uma das mais recorrentes solicitações durante o FG, pois servirá para melhorar o conforto da espera na sala. Todos os itens da bancada foram planejados para terem suas posições fixas, de forma que os usuários, que são PcDV, sempre saibam onde estão localizados os utensílios. Foram projetados pufes para dar suporte às atividades multifuncionais da sala, como tocar violão e cantar. $\mathrm{O}$ armário aéreo será destinado para armazenamento diverso.

Na vista 3 (Figura 15a) houve a elaboração de um nicho que será composto por vegetações aromáticas, como alecrim ou hortelã. Pallasmaa (2012) afirma que explorar outros sentidos é, para as PcDV, de essencial 
importância para que o espaço arquitetônico seja compreendido como o espaço vivido, que possa transcender a geometria ou mensurabilidade da beleza.

Para o projeto da vista 4 , conforme Figura 15 b, foi necessário encontrar soluções para melhorar a incidência de luz, ocasionada por uma janela que ocupa a extensão de quase toda a parede e atrapalha a mobilidade das PcDV com baixa visão. O controle do excesso de luminosidade ocorre no projeto por meio do bloqueio de duas folhas da janela existente utilizando um painel verde, no qual serão colocadas mais vegetações aromáticas, e por meio de uma mesa retrátil que será utilizada aos finais de semana para as atividades de venda de produtos. Essa mesa foi projetada para que durante a semana possa servir de mural, com papel lousa, para informar aos visitantes as atividades acontecendo. Nessa vista também foi planejado um gancho alto para pendurar um violão e ganchos mais baixos para pendurar casacos. As cadeiras serão retráteis para que os usuários possam sentar-se ao chão e usufruir do piso de carpete, pensado e elaborado para as atividades de canto e violão. Projetou-se uma mesa de canto para que estejam disponíveis panfletos de apresentação para visitantes ou livros em braile.

Após a elaboração do projeto do interior da sala, iniciou-se a etapa de fabricação da maquete tátil (Figura 16).

A maquete tátil foi apresentada (Figura 17) aos mesmos participantes do FG, que ao manusearem a maquete puderam sentir o estofado das cadeiras retráteis, as diferentes texturas definidas para o piso, a vegetação dos painéis verdes, o piso tátil, bem como a abertura dos armários, da porta de acesso e a retratibilidade dos móveis, que foram planejados para poderem ser movimentados e fixados, quando necessário.

$\mathrm{Na}$ percepção dos participantes, os resultados do projeto foram satisfatórios e eles relataram terem se surpreendido com o cuidado e o detalhamento para que todas as solicitações fossem atendidas. A sala foi reconhecida por apresentar facilidade de uso para todos os participantes, que identificaram rapidamente o acesso, a janela existente e os demais detalhes. Os demais materiais e objetos também foram identificados pelos participantes com facilidade.

Figura 15 - Detalhamento das vistas 1 e 2 da sala de recepção/espera

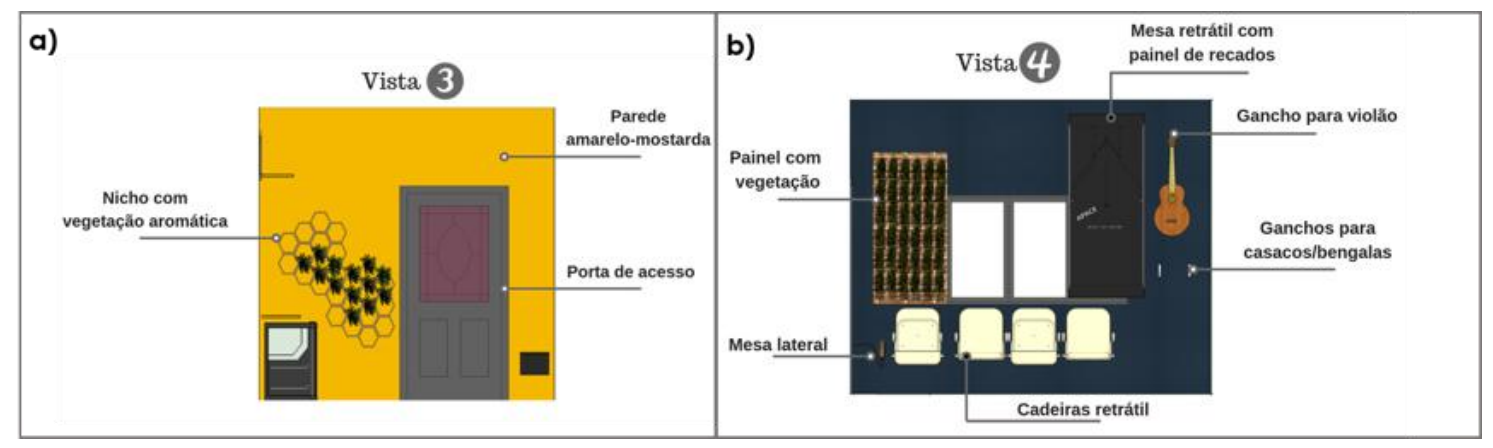

Figura 16 - Montagem da maquete tátil em laboratório

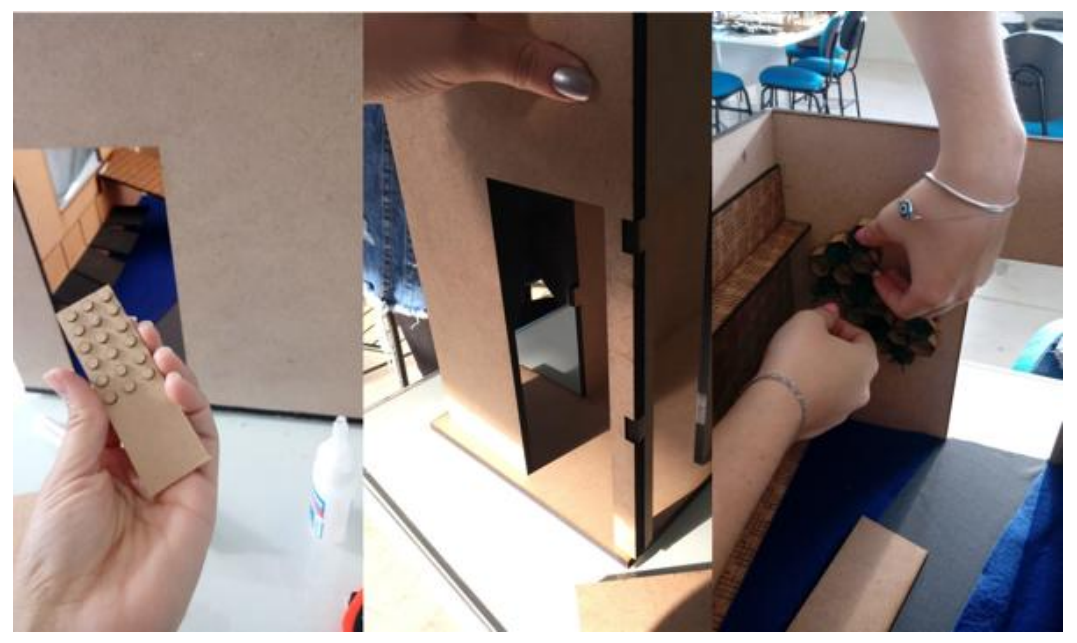


Figura 17 - Interação com a maquete tátil

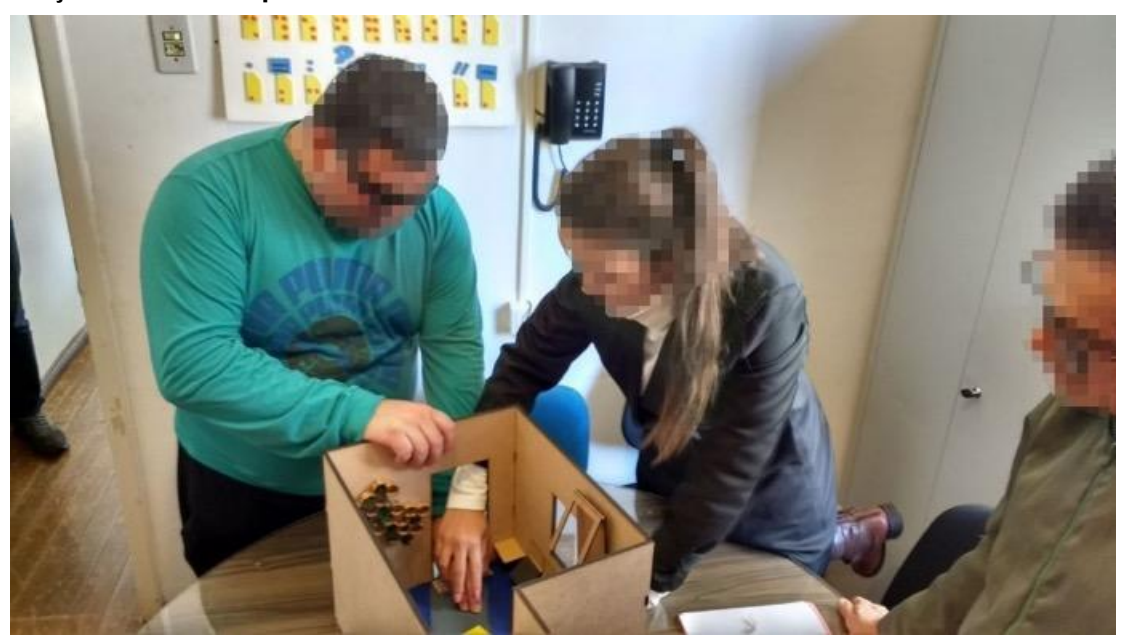

No que se refere à área externa, durante o FG foi possível perceber o comprometimento dos participantes em tentar não somente pensar em seus próprios desejos, mas também buscar elementos que satisfizessem os demais associados que não estavam presentes. Para a proposta da área externa (Figura 18), foi realizada a composição de pisos para melhor direcionamento dos usuários, e, por isso, o eixo direcional seguiu o mesmo padrão da sala de espera/recepção. Para o restante da área externa a proposta foi de um piso escuro emborrachado. Essa decisão é uma tentativa de padronizar o piso da sede que atualmente é composto por parquet escuro envelhecido e por uma calçada externa desgastada.

$\mathrm{Na}$ vista 5 (Figura 19a) observa-se a inserção de uma fonte de água como um elemento sonoro que trará acolhimento e aconchego para os usuários. Áreas verdes foram implantadas por meio de canteiros e painéis verdes para a plantação de flores e folhas aromáticas. Os brinquedos para área de recreação das crianças foram reaproveitados, sendo que o escorregador foi substituído somente pelo brinquedo desenvolvido nesta pesquisa.

Devido às reclamações da falta de segurança, ocasionada pela grande visibilidade que a grade da edificação possui, elaborou-se para a vista 6 (Figura 19b) um sistema de vegetação de trepadeiras que dificulta a visibilidade dos transeuntes da rua ao interior da área de convívio. Na vista 7 (Figura 19c) observa-se a colocação de bancos de madeira e a continuação da vegetação trepadeira na grade.

\section{Projeto colaborativo: etapa com crianças}

O PC com as crianças teve como objetivo desenvolver elementos recreativos que explorassem habilidades necessárias ao seu desenvolvimento e que, ao mesmo tempo, ofereçam oportunidades de interação entre as crianças atendidas pela Associação de Cegos e crianças que, eventualmente, frequentam a associação acompanhando algum familiar.

O primeiro brinquedo (Figura 20), elaborado para o espaço interno, busca desenvolver a parte cognitiva da criança, por meio de encaixes de figuras geométricas, elementos sonoros, letras, números e brinquedos diversos fixados por meio de velcro. Esses brinquedos foram selecionados com base na interação com a voluntária da associação, participante do PC, bem como considerando sugestão dos responsáveis pelas crianças que indicaram os brinquedos que as crianças mais gostam de manipular.

O segundo brinquedo, elaborado na disciplina de fabricação digital e prototipagem rápida do $4^{\circ}$ semestre de arquitetura e urbanismo, teve briefing de uma criança com deficiência visual. $\mathrm{O}$ brinquedo foi elaborado durante a disciplina e fabricado em tamanho real para sua efetiva utilização. Ele se encaixou perfeitamente ao briefing infantil das crianças da Associação de Cegos, visto que, de todas as atividades disponíveis em parquinhos, aquela que as crianças mais salientaram durante o FG foi a do escorregador. Na ocasião as crianças puderam experimentar o brinquedo (Figura 21), acompanhadas por seus responsáveis, que relataram em que momentos o brinquedo apresentava perigo ou quais seriam as possibilidades de melhoria visando melhorar a segurança das crianças.

A partir da colaboração do grupo de participantes, o brinquedo deverá passar por novas modificações e será testado. Também será aprimorado por meio de uso da fabricação digital e automação, utilizando 
programação em arduino, sensores e atuadores, que irão possibilitar a emissão de um som quando a criança chegar ao patamar do escorrega e acionar as luzes das laterais (fita LED) da rampa.

Figura 18 - Leiaute da área externa

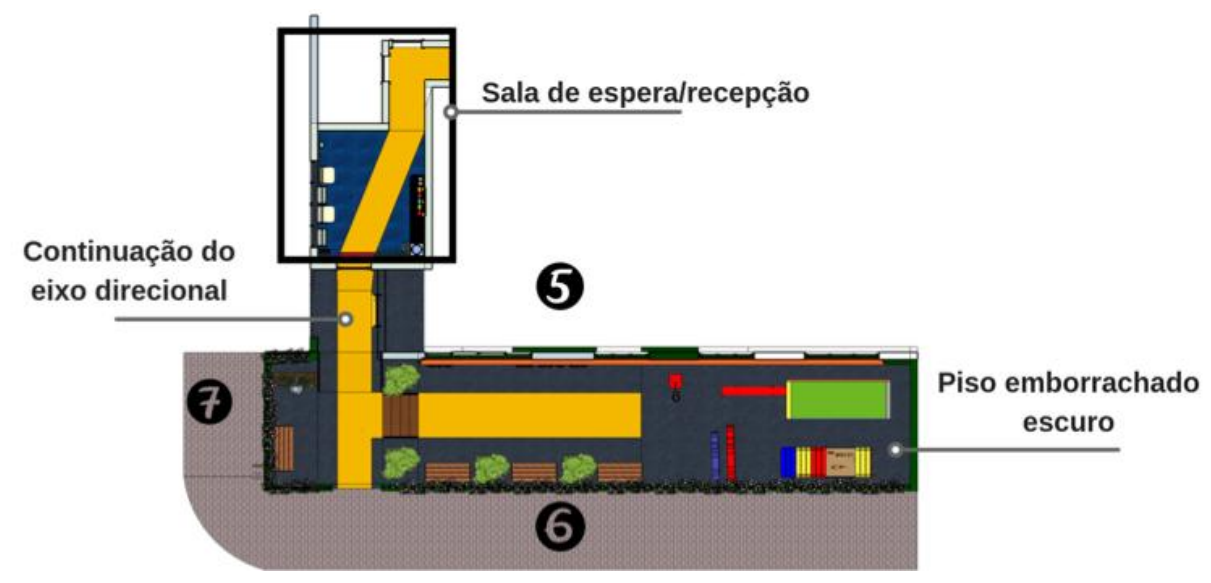

Figura 19 - Vistas 5, 6 e 7 desenvolvidas para a área externa

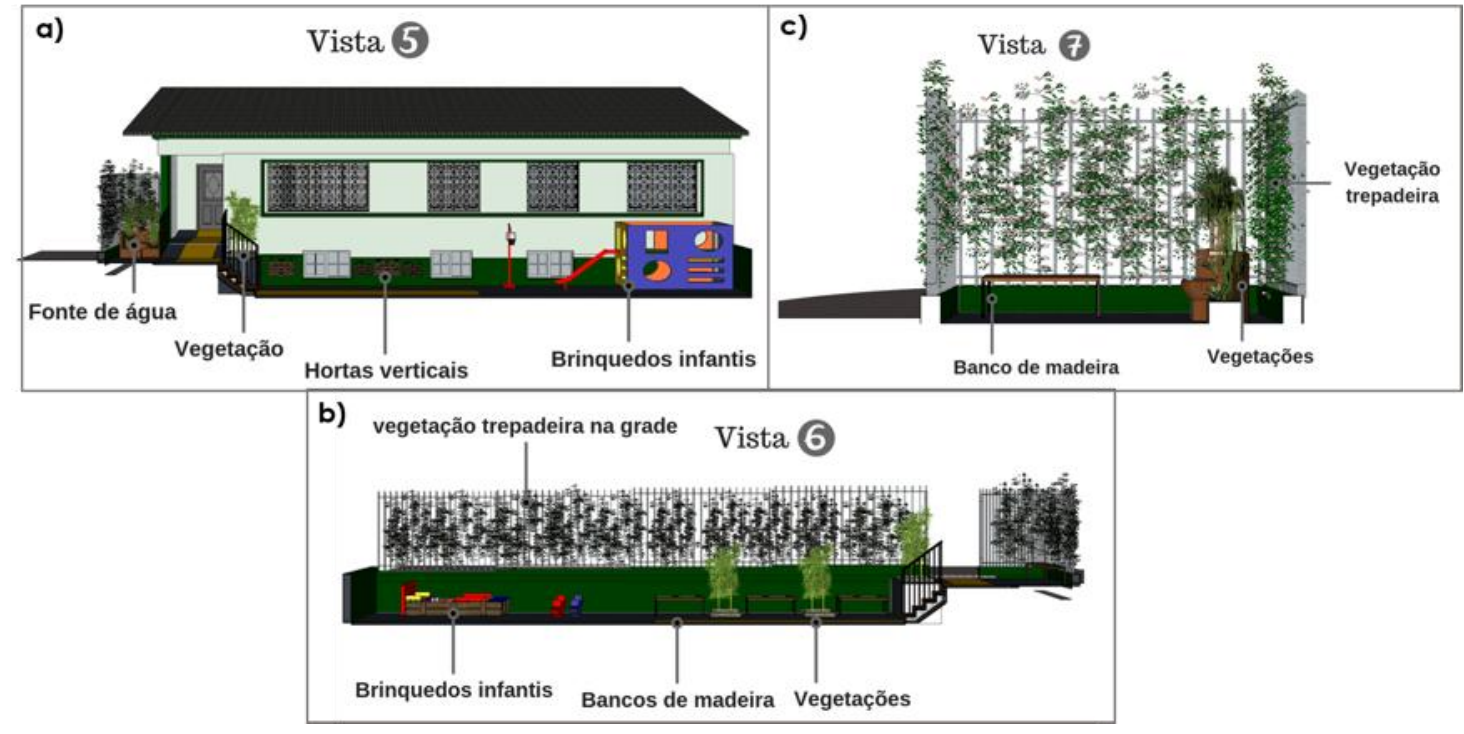

Figura 20 - Brinquedo desenvolvido para a sala de recepção/espera

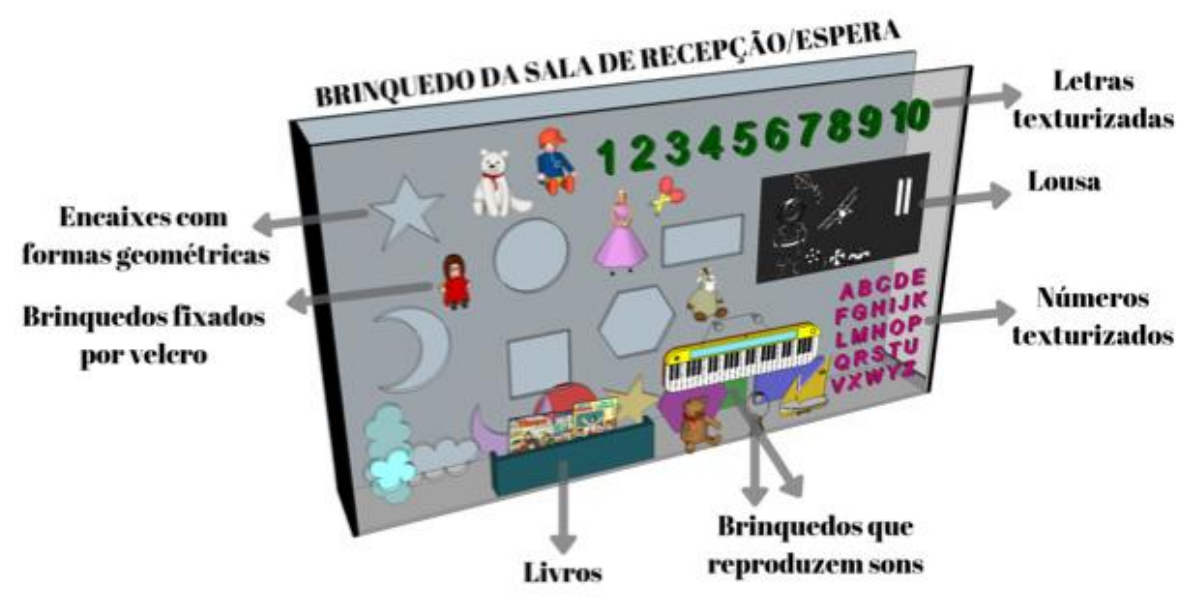


Figura 21 - Protótipo do brinquedo

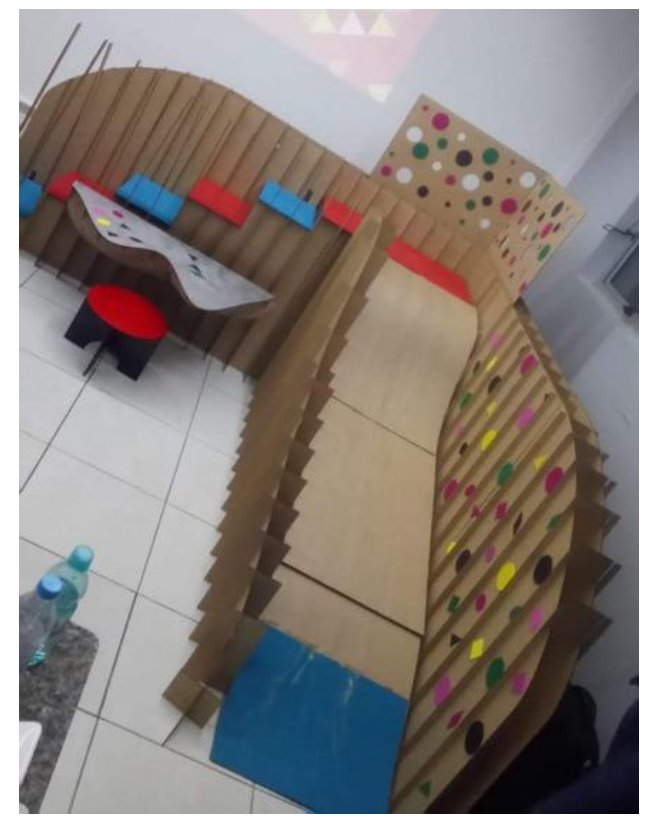

\section{Conclusão}

A metodologia de projeto colaborativo ou codesign em desenvolvimento nesta pesquisa é ampla e não vem sendo desenvolvida em um momento isolado ou com vistas ao desenvolvimento de um único projeto. A interação entre projetistas e PcDV e a compreensão da dinâmica de uso e apropriação dos ambientes construídos, bem como da projetação deles, é um processo que está sendo construído por meio de várias ações conjuntas ao longo dos seis anos de desenvolvimento do projeto principal de pesquisa.

Conforme apresentado, a efetividade e interação na construção conjunta do projeto desenvolvido com as PcDV da associação não aconteceram somente durante o desenvolvimento das propostas de requalificação dos ambientes da recepção e do espaço externo da sede atual da associação.

Há uma reciprocidade de aprendizado entre as PcDV e os projetistas no processo de codesign, no instante que emergem em situações não vivenciadas em seu cotidiano. As PcDV se deparam com instrumentos de comunicação e representação do ambiente construído não familiares em seu cotidiano ${ }^{5}$, bem como se colocam como agentes da concepção de um projeto, enquanto estão centradas na primazia da visão e nas sensações oportunizadas por ela. Uma das principais contribuições que a experiência de codesignaqui relatada oportuniza é a reflexão do quanto os projetos são concebidos sem a consideração de todas as potencialidades de sensações que o ambiente pode permitir a quem o usufrui.

Além do mais, a interação com as PcDV no processo de projeto ratifica e retifica o que a normatização e a legislação preconizam. Exemplo disso foi a opinião das PcDV sobre a não necessidade do piso tátil direcional e sim o de alerta, o contraste de cores, as texturas, o leiaute e a manutenção do mobiliário no mesmo lugar, podendo ter mutações, porém permanecendo na mesma localização.

A preferência por guias de balizamento em vez de pisos táteis direcionais pelos associados também foi verificada (CESARO; SILVA; MUSSI, 2019). Na normativa americana a obrigatoriedade de piso tátil direcional foi eliminada, mantendo somente o piso tátil de alerta (SILVA et al., 2019).

Ao mesmo tempo, as ações de codesign desmistificam ideias preconcebidas, por exemplo, a ideia de que basta ter sinalização em braile e elementos com esse tipo de comunicação para a interação das PcDV e o ambiente. Os focus group e workshops com os membros da associação apontaram que menos de $20 \%$ leem em braile. A National Federation of the Blind (2009) ressalta que poucas pessoas com baixa visão leem em braile, preferindo o aumento de fontes e estilos de texto.

${ }^{5}$ As ações e representações usadas não faziam parte do cotidiano das PcDV participantes. 
A concepção, representação e ensino do projeto de arquitetura, urbanismo, paisagismo e interiores são majoritariamente visuais (HEYLIGHEN; HERSSENS, 2014; MAGNUSSON; HEDVALL; CALTENCO, 2018). Ações desse tipo permitem uma compreensão do usuário e a construção conjunta e maior assertividade das decisões projetuais, em uma mão dupla de aprendizado entre projetistas e PcDV.

O codesign pode ajudar a ter maior entendimento sobre o usuário e projetar com ele e não somente para ele (CAIXETA; FABRÍCIO, 2018; MAGNUSSON; HEDVALL; CALTENCO, 2018), contribuindo, portanto, para uma equalização entre os saberes do projetista e das PcDV, também usuárias do espaço a projetar. A inclusão das PcDV no processo de projeto contribui para educação do projetista e a diminuição da onipresença nas decisões projetuais, aproximando-os das reais necessidades dos usuários. A participação das PcDV no processo valoriza sua expertise e contribui para uma inclusão mais efetiva.

A efetividade do codesign ocorre quando é viabilizada a participação na concepção do projeto e a interação ativa ente os projetistas e os usuários efetivos, trocando expertises, aprendendo mutuamente e cocriando alternativas mais assertivas para o projeto, as quais aumentarão as chances de apropriação e pertencimento a ele. O codesign difere de um processo tradicional de projeto, pela intensidade da interatividade e quão complementares são as ações, expertises e vivências de cada um dos agentes envolvidos no processo. Dessa forma, observa-se o quanto se torna dependente a necessidade de construção conjunta e validação dos resultados, em um contínuo cocriar - feedback - cocriar - feedback, ou seja, a cocriação na concepção do projeto em si e nos métodos de interação e comunicação e o feedback constante do processo por projetistas e usuários.

Embora o codesign seja um processo de empatia e de abolição da onipresença do projetista, ele mantém alguns momentos de ações individuais dos projetistas, por exemplo, na representação, comunicação e interpretação das necessidades e saberes do usuário. É um exercício de considerar o outro e sentir a necessidade da expertise do outro, principalmente quando se trata de projetar para PcDV, e os projetistas não possuem a vivência de ser uma PcDV. O processo extrapola a mera consulta das necessidades e a validação restrita do produto, para a inserção e colaboração do usuário no processo e não somente no produto do projeto.

As principais contribuições desta pesquisa estão no relato da metodologia empregada para codesign de interiores e paisagismo aplicada a PcDV adultas. Representações concretas como a maquete tátil mostraramse adequadas para estabelecer uma linguagem comum de projeto de arquitetura de interiores. A etapa do PC com as crianças, por outro lado, foi uma primeira experiência com pouca influência direta no projeto, exigindo pesquisas mais aprofundadas. Sugere-se também que sejam realizadas entrevistas com terapeutas ocupacionais para dar maior escalabilidade e ampliação da percepção das projetistas.

Percebeu-se ao longo do estudo que, às vezes, as PcDV participantes se sentiam tão emocionadas em poder sentir o espaço e antecipar o novo ambiente construído que deixavam de apontar suas percepções, havendo a necessidade de mediação e incentivo constante para o contínuo compartilhamento de ideias, expertises e mudanças desejadas. Isso relacionado aos projetos concretos em si, pois a expertise e as impressões gerais de mobilidade, materiais, comunicação e representação são amplamente debatidas desde o início do projeto. Esse fato reforça a importância da relação entre os atores envolvidos e o incremento do aprendizado.

O codesign proporciona transformações tanto para a forma como o arquiteto projeta ambientes voltados às PcDV, como para a forma como as PcDV conseguem se tornar parte do processo de projeto. E a cada ciclo se fazem novas descobertas e abrem-se novos caminhos para que se desenvolva uma linguagem comum de projeto entre arquitetos e PcDV.

Apesar de a pesquisa apresentada ter foco nas PcDV, a definição de uma metodologia de codesign pode ter escalabilidade para outros segmentos da sociedade, considerando ser a essência desse método o projeto centrado nas pessoas, independentemente do segmento envolvido. Os produtos e processos de projeto gerados ou em andamento pela prática do codesign experenciadas nos focus group, passeios acompanhados e workshops realizados com as PcDV, no âmbito do grupo de pesquisa, podem, com a sistematização das ações feitas e com sua continuidade, fornecer elementos importantes para essa metodologia.

\section{Referências}

ABATE, T. P.; KOWALTOWSKI, D. C. C. K. Avaliação de pisos táteis como elemento de wayfinding em escola de ensino especial para crianças com deficiência visual. Ambiente Construído, Porto Alegre, v. 17, n. 2, p. 53-71, abr./jun. 2017. 
ASSOCIAÇÃO BRASILEIRA DE NORMAS TÉCNICAS. NBR 16537: acessibilidade: sinalização tátil no piso: diretrizes para elaboração de projetos e instalação. Rio de Janeiro, 2016.

BIANCHIN, M.; HEYLIGHEN, A. Just design. Design Studies, v. 54, p. 1-22, jan. 2018.

CAIXETA, M. C. B. F.; FABRICIO, M. M. Métodos e instrumentos de apoio ao codesign no processo de projeto 111 de edifícios. Ambiente Construído, Porto Alegre, v. 18, n. 1, p. 111-131, jan./mar. 2018.

CARNEIRO, G.; BARROS, G.; ZIBEL, C. Design colaborativo de comportamentos para ambientes interativos. V!RUS, São Carlos, v. 6, dez. 2011.

CAVALCANTI, V. P.; ANDRADE, A. M. Q.; SILVA, G. D. A. Modos de fazer: uma experiência em processo de criação compartilhado e modelo de atuação transdisciplinar na relação entre design e artesanato. V!RUS, São Carlos, n. 6, dez. 2011.

CESARO, S. R. et al. Eyespace: projeto colaborativo de um óculos para pessoas com deficiência visual no cenário internet ofthings In: SIMPÓSIO BRASILEIRO DE TECNOLOGIA DA INFORMAÇÃO E COMUNICAÇÃO NA CONSTRUÇÃO, Campinas, 2019. In: SIMPÓSIO BRASILEIRO DE TECNOLOGIA DA INFORMAÇÃO E COMUNICAÇÃO NA CONSTRUÇÃO, Porto Alegre, 2019. Anais [...] Porto Alegre: ANTAC, 2019.

CESARO, S. R.; SILVA, L. B. O.; MUSSI, A. Q. Maquete tátil de ambiente interno: experiência com impressora 3D para pessoas com deficiência visual In: MOSTRA DE INICIAÇÃO CIENTÍFICA E EXTENSÃO COMUNITÁRIA, 13.; MOSTRA DE PESQUISA DE PÓS-GRADUAÇÃO, 12., Passo Fundo, 2019. Anais [...] Passo Fundo, 2019b.

CESARO, S. R.; SILVA, L. B. O.; MUSSI, A. Q. Maquete tátil urbana: uma experiência com Impressora 3D para pessoas com deficiência visual In: SEMINÁRIO DE ARQUITETURA E URBANISMO: CONTRASTES-DIREITO À CIDADE E O MERCADO IMOBILIÁRIO, Passo Fundo, 2019. Anais [...] Passo Fundo: IMED, 2019a.

FLUGLERUD, K. S. Inclusive design of ICT: the challenge of diversity. Oslo, 2014.Thesis - University of Oslo, Oslo, 2014.

HEYLIGHEN, A.; HERSSENS, J. Designerly ways of not knowing: what designers can learn about space from people who are blind. Journal of Urban Design, v. 19, n. 3, p.317-332, 10 mar. 2014.

HOURCADE, J. P. Interaction design and children. Fundation and Trends® in human computer interaction, v. 1, n. 4, p. 277-392, 2008.

HUANG, C.-H.; YU, S.-C. A study of environmental perception patterns of the visually impaired and environmental design. Indoor and Built Environment, v. 22, n. 5, p. 743-749, 12 set. 2012.

LAHAV, O.; MIODUSER, D. Blind personsacquisition of spatial cognitive mapping and orientation skills supported by virtual environment. In: INTERNACIONAL CONFERENCE DISABILITY, 5., Oxford, 2004. Proceedings [...] Oxford, 2004.

LAHAV, O.; SCHLOERB, D. W.; SRINIVASAN, M. A. Integrate the BlindAid system in a traditional orientation and mobility rehabilitation program. In:VIRTUAL REHABILITATION INTERNATIONAL CONFERENCE, Israel, 2009. Proceedings [...] Israel, 2009.

MAGNUSSON, C.; HEDVALL, P.; CALTENCO, H. Co-designing together with Persons with Visual Impairments. In: PISSAULOX, E.; VELÁSQUEZ, R. Mobility of visually impaired people: fundamentals and ICT Assistive Technologies. New York: Springer International Publishing, 2018.

MORGAN, D. L. Focus groups as qualitative research: planning and research design for Focus Group. London: Sage, 1997.

MUSSI, A. Q. et al. Arquitetura inclusiva: a planta tátil como instrumento de projeto colaborativo com portadores de deficiência visual. In: CONGRESO DE LA SOCIEDAD IBEROAMERICANA DE GRÁFICA DIGITAL, 20., Buenos Aires, 2016. Anais [...] Buenos Aires, SiGraDI, 2016.

MUSSI, A. Q. et al. Welfare increase tools for blind and visually impaired people: inclusive design and tactile model. Arquiteturarevista, v.15, p. 1-14, 2019.

NATIONAL FEDERATION OF THE BLIND. The Braille literacy crisis in America: facing the Truth. Reversing the Trend, Empowering the Blind, 2009.

PALLASMAA, J. The eyes of the skin: architecture and the senses. New Delhi: Wiley, 2012. 
SCHNEIDER, A. A.; SILVA, T. L.; MUSSI, A. Q. Modelos hápticos tecnológicos que auxiliam na mobilidade de pessoas com deficiência visual. In: MOSTRA DE INICIAÇÃO CIENTÍFICA E EXTENSÃO COMUNITÁRIA, 13.; MOSTRA DE PESQUISA DE PÓS-GRADUAÇÃ̃O, 12., Passo Fundo, 2019. Anais [...] Passo Fundo: IMED, 2019.

SILVA, L. B. O. et al. Piso tátil: Revisão Sistemática e seu uso por Pessoas com Deficiência Visual. In: MOSTRA DE INICIAÇÃO CIENTÍFICA E EXTENSÃO COMUNITÁRIA, 13.; MOSTRA DE PESQUISA DE PÓS-GRADUAÇÃO, 12., Passo Fundo, 2019. Anais [...] Passo Fundo, IMED, 2019.

SILVA, L. B. O. Projeto arquitetônico inclusivo: orientação espacial por piso tátil e uso de tecnologias digitais como qualificação do processo de projeto em arquitetura. Passo Fundo, 2020. 182 f. Dissertação (Mestrado em Arquitetura e Urbanismo) - Programa de Pós-Graduação em Arquitetura e Urbanismo, IMED, Passo Fundo, 2020.

SILVA, L. B. O.; MUSSI, A. Q.; SILVA, T. L. Inclusive architecture: digital technologies and qualification of the project process. In: eCAADe, 37.;SIGraDi Conference, 23., Porto, 2019. Proceedings [...] Porto: University of Porto, 2019a.

SILVA, L. B. O.; MUSSI, A. Q.; SILVA, T. L. Qualificação do processo de projeto inclusivo: programação de software BIM In: SEMINÁRIO DE ARQUITETURA E URBANISMO: CONTRASTES-DIREITO Å CIDADE E O MERCADO IMOBILIÁRIO, Passo Fundo, 2019. Anais [...] Passo Fundo: IMED, $2019 \mathrm{~b}$.

SILVA, L. B. O.; PORTELLA, J.; MUSSI, A. Q. Arquitetura inclusiva: uma experiência de projeto colaborativo para pessoas com deficiência visual. In: ENCONTRO DA ASSOCIAÇÃO NACIONAL DE PESQUISA E PÓS-GRADUAÇÃO EM ARQUITETURA E URBANISMO, 5., Salvador, 2018. Anais [...] Salvador: FAUFBA, 2018.

\section{Agradecimentos}

Agradecemos a Associação Passofundense de Cegos - APACE e os entrevistados pela importante contribuição científica a este trabalho de pesquisa; a Fundação IMED; o Núcleo de Inovação e Tecnologia em Arquitetura e Urbanismo (NITAU) do Programa de Pós-graduação em Arquitetura e Urbanismo da Faculdade Meridional (PPGARQ/IMED); o apoio da Coordenação de Aperfeiçoamento de Pessoal de Nível Superior - Brasil (CAPES) - Código de Financiamento 001; e o Conselho Nacional de Desenvolvimento Científico e Tecnológico - CNPq. 
Andréa Quadrado Mussi

Programa de Pós-Graduação em Arquitetura e Urbanismo | IMED | Rua Senador Pinheiro, 304 | Passo Fundo - RS - Brasil | CEP 99070-220 | Tel.: (54) 3045-6100 | E-mail: andrea.mussi@imed.edu.br

\section{Luísa Batista de Oliveira Silva}

Programa de Pós-Graduação em Arquitetura e Urbanismo | IMED | E-mail: luisa.projetospredilar@gmail.com

Elvira Maria Vieira Lantelme

Programa de Pós-Graduação em Engenharia Civil | IMED | E-mail: elvira.lantelme@imed.edu.br

Sara Rossato de Cesaro

Curso de Arquitetura e Urbanismo | IMED | E-mail: saradecesaro@hotmail.com

Luísa Fernanda NercolinoDeon

Programa de Pós-Graduação em Arquitetura e Urbanismo | IMED | E-mail: luisa.deon@hotmail.com

Daiara lasmin Rodrigues

Curso de Arquitetura e Urbanismo | IMED | E-mail: daiarair@hotmail.com

Thaísa Leal da Silva

Programa de Pós-Graduação em Arquitetura e Urbanismo | IMED | E-mail: thaisa.silva@imed.edu.br

Ambiente Construído

Revista da Associação Nacional de Tecnologia do Ambiente Construído

Av. Osvaldo Aranha, $99-3^{\circ}$ andar, Centro

Porto Alegre - RS - Brasil CEP $90035-190$

Telefone: +55 (51) 3308-4084

Fax: +55 (51) 3308-4054

www.seer.ufrgs.br/ambienteconstruido

E-mail: ambienteconstruido@ufrgs.br

This is an open-access article distributed under the terms of the Creative Commons Attribution License.

386 Mussi,A. Q.; Silva, L. B. de O.; Lantelme, E. M. V.; Cesaro, S. R. de; Deon, L. F. N.; Rodrigues, D. I.; Silva, T. L. da 